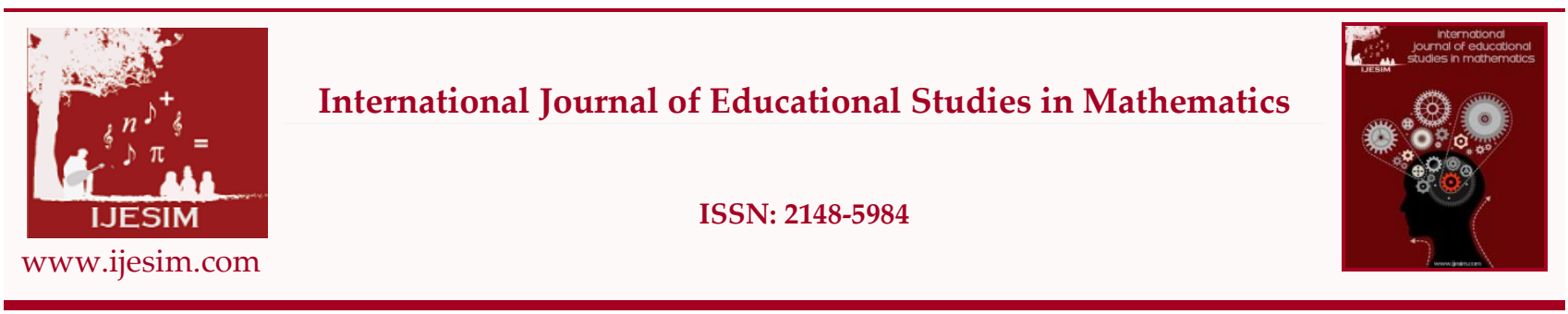

\title{
Students' Development of The Relationship Between The Cartesian Product, Relation and The Definition of Function
}

\author{
Gülseren Karagöz Akar1', Beyhan Şener²
}

${ }^{1}$ Bogazici University, ${ }^{2}$ Maltepe University

\begin{abstract}
This study investigated the students' development of the relationship between the Cartesian Product, relation and the function concepts. Six 9th grade students in a private school participated in mathematics lessons, 4 hours per week for four consecutive weeks. Students were asked to engage in GeoGebra and non-GeoGebra Tasks through focused questioning. Data from the transcripts of the audiotapes of the classroom discussions and the teacher's reflections together with the written artifacts from the students were analyzed. Results revealed that students came to the understanding of the Cartesian Product between two sets as the matching of all elements in the sets. Results also indicated that students were able to detect why the elements of a Cartesian Product needs to be in ordered pairs. In addition, students were able to determine the graph of a function and a relation given a graph of a Cartesian Product and explain how they are related to each other. Data further pointed to some student difficulties in graphing a Cartesian Product defined on two finite and infinite sets and in considering equal sign as showing the output in terms of the input values. In this paper, we intend to contribute to the field by showing the kinds of students' reasoning on their development of the relationship between these concepts. Also, we propose a set of GeoGebra and non-GeoGebra tasks and problems developing and assessing such relationships.
\end{abstract}

Keywords:

Cartesian Product, alternative definitions of function, high school students, GeoGebraTasks

(C) 2014 IJESIM. All rights reserved

Article History:

Received 03.04.2014 Received in revised form 18.04.2014 Accepted 30.04.2014 Available online 01.06.2014

\section{Introduction}

The concept of function has been investigated to a great extend in the mathematics education field (e.g., Breidenbach, Dubinsky, Hawks, \& Nichols, 1992; Carlson, 1998; Carlson, Jacobs, Coe, Larsen, \& Hsu, 2002; Dubinsky \& Harel, 1992; Sfard, 1991). Researchers pointed out to the importance of the definition of function from two different perspectives, based on relations, and, based on dependent and independent variables. The first definition requires students to think of function in terms of matching elements of two sets such that for every element of a non-empty set A, there exists one and only one element of a non-empty set B (Dabbah, Nurlu, Onder, 1992). The second definition requires students to think of function as a relationship between two covarying quantities (e.g., Carlson \& Oehrtman, 2005), the process understanding of function (Dubinsky \& Harel, 1992). Carlson \& Oehrtman (2005) claimed,

"the educational research literature are pointing the way for future curricular interventions to assist students in developing a robust function conception - a conception that includes a view of function as an entity that accepts input and produces output and enables reasoning about dynamic mathematical content and scientific contexts"

\footnotetext{
${ }^{1}$ Corresponding author's address: Secondary School Science and Mathematics Education Department, Bogazıcı University, Turkey 
This suggests that the definition of function depending on matching elements of two sets, where the elements of the first set is seen as the input and the elements of the second set is seen as the output; and, the definition of function depending on constructing a relationship between two covarying quantities (Carlson, Smith \& Persson, 2003) both need to be established on the students part. Researchers claimed that the first definition is a requirement because for the second definition all the elements of the first set (the domain) (Dabbah et.al., 1992) needs to be taken into account (Bayazit \& Aksoy, 2013), too. By the same token, researchers claimed that the definition of function based on the independent and dependent variables is a requirement because this dynamic view of function is "foundational for understanding major concepts in advance mathematics (e.g., Carlson \& Oehrtman, 2005). In a similar vein, Sfard (1991) argued for the need to establish the relationship between the Cartesian Product, relations and the definition of function on the students part.

In this regard, this study aimed at investigating $9^{\text {th }}$ grade students' construction of the relationship between Cartesian Product, relations and function and their construction of the definition of function. The research questions were two fold:

1- How do six $9^{\text {th }}$ grade students construct the relationship between the Cartesian product, the relations and the function by defining them in terms of each other and showing their relationships in graphs?

2- What specific GeoGebra and non-GeoGebra tasks and specific questioning might facilitate such construction on their part?

In this study, the first author conducted teaching experiments in collaboration with a teacher (Cobb, 2000), the second author, teaching at a private school at the time of the data collection. The purpose of conducting teaching experiments in collaboration with teachers is not to generalize the results as in the traditional sense (Cobb, 2000). However, "...what is generalized is a way of interpretting and acting that preserves the specific characteristics of individual cases. (Cobb, 2000). In this regard, the purpose of this research is to feed to inform future teachings (Cobb, 2000).

In this paper, we report on the data from six $9^{\text {th }}$ grade students. The focus of analysis was the students' reasoning through tasks during the whole-class discussions, some students' reasoning through assessment problems and the teacher's reflections on what, how and why students learnt. We also show the tasks constructed by the two authors for such intervention. Based on these students' development of the relationship among the three concepts, we explicated on the relationships that might possibly be triggered through engaging in the kinds of GeoGebra and non-GeoGebra practices in a mathematics classroom.

In the next section, based on the previous research results, we explain our views on the Cartesian Product, relations, and the function concept and the relationships among them.

\section{Conceptual Framework}

Cartesian Product comprises the basis of many concepts in mathematics such as functions (Bayazit, 2010), space to the $n$th degree where $n$ is Natural number (Karacay, 2009) and geometrical objects' projections in the analytical plane (Narll, 2013). Therefore, constructing a robust understanding of what Cartesian Product means and how it mathematizes the real life situations on the students' part become important (e.g., Dubinsky \& Harel. 1992). Particularly, students need to realize that a Cartesian Product between any two sets (finite or infinite) means all the matchings between the elements of them (Narll, 2013). Also they need to be able to state the relationships between a relation and a function such that every relation is a subset of any Cartesian Product defined on the same sets and a function is a special kind of relation; therefore, a subset of the Cartesian Product (Eccles, 1997). On the other hand, Sfard (1991) stated that students' development of such a chain of reasoning requires studensts to think of any subset's potentiality for being a function and this is a higher level of reasoning on their part; i.e., function being a mental object. Yet, she suggested for the students' development of such awareness. This study aimed at providing students with opportunities to develop the relationship among these three concepts.

Researchers claimed that students' realizing the relationships among these concepts as Sfard (1991) 
pointed to might help them construct different definitions of function (Cooney et.al., 2011) necessary for advanced mathematical understandings (e.g., Carlson \& Oerthman, 2005). That is, conceiving function dynamically, as the mechanism creating a relationship between two co-varying quantities (e.g., Carlson \& Oerthman, 2005; Karagoz Akar, 2013, 2010) comprises conceiving function as a relation matching the elements of two sets (Bayazit \& Aksoy, 2013). This is because covariation between the elements of two sets already creates a matching between these elements (Bayazıt \& Aksoy, 2013). This in turn requires one to at least have a process understanding of function (Dubinsky \& Harel, 1992) since "students can imagine all input at once or "run through" a continuum of inputs" (Carlson \& Oerthman, 2005). In this regard, students might develop a definition of function such that "a function is a relation in which each element of the domain is paired with exactly one element of the range" or "a function is a set of ordered pairs (or number pairs) that satisfies this condition: There are no two ordered pairs with the same input and different outputs" (Cooney, Beckmann, Lloyd, Wilson \& Zbiek, 2011). Students might also define function as the following: "a function is a relationship between input and output. In a function the output depends on the input. There is exactly one output for each input" (Cooney, et.al., 2011). The purpose of this study was to investigate how students might develop such relationships among the three concepts such that they might view function dynamically, as covarying quantities rather than imagining a single value at a time as input or output (Carlson \& Oerthman, 2005).

By the same token, students' lack of knowledge in how the Cartesian Product mathemathizes real life situations might cause deficits in their realization of the importance of order in number pairs. This, in turn, might create difficulties on their part, in terms of their understanding of functions or different representations of it, such as a list representation (e.g., Bayazıt, 2010; Dubinsky \& Harel, 1992). In this regard, real life situations that are compatible with students' own lives might be used to trigger meaning regarding the number pairs (Narl1, 2013). In this study, to create such awareness, we constructed tasks exemplifying real life situations. In addition, research showed that over emphasis on the procedural rules on finding the equation of lines, students come to internalize that any function rule needs to be based on continuous variables (e.g., Leinhardt, Zaslavsky \& Stein, 1990) and that a line is composed of two points, rather than infinitely many points (Dunham \& Osborne, 1991). This study also pointed to students' difficulties while developing a relationship among the Cartesian Product, relation and definition of function.

\section{Method}

\section{Participants}

Six 9th grade students at a Private School in Istanbul, Turkey, have participated in the study. All of the students had very low grades in mathematics. We choose to work with these students since the second author was a mathematics teacher in that school and teaching these students.

\section{Data Collection}

The method of the study was conducting teaching experiments in collaboration with teachers (Cobb, 2000). The purpose of such methodology is to both support students' development of a particular area of mathematics and also discuss the particular classroom events. Data were collected for a total of four weeks during the mathematics course. The mathematics course was four hours per week. The first author and the second author constructed the tasks for the teaching sessions prior to each mathematics lesson. The second author taught all the lessons. During the lessons, for the tasks on GeoGebra, the Turkish version was used. Then, the two authors discussed how the teaching went after each teaching session. Then, based on the teacher's reflections on how students reasoned during the classes, they revised the tasks to be used in the next teaching session. All of the lessons were audio-taped and the second-author wrote reflections regulary after each teaching session. The audio-taped data were then transcribed by the second-author. Also, students' written artifacts to the answers on the within-class questions were kept for analysis. 


\section{Data Analysis}

At the beginning of the study, the second author gave problems to the students to assess their background knowledge on the "set" content since it is a prerequsite for the function and the Cartesian Product contents (Narll, 2013). At the end of the teaching sessions, an assessment examining the relationships among the Cartesian Product, the relation and the function has been given to the students. We did a line-by-line analysis of the transcribed data from each teaching session, the teacher's (second author) regular reflections on her students' thinking right after each teaching session, and students' written artifacts from the within-class questions. During the analysis, we focused on two things: first, the meanings the students attributed to the contents they were learning during each session, their reasoning and justifications on the relationships among the contents, and the changes in these meanings. Secondly, we focused on possible practices such as whole class discussions, non GoeGebra and GeoGebra tasks that might have produced the changes in their meanings. Third, we checked if there was any anomolies in the data. In this regard, both ongoing analysis and the retrospective analysis was done (Cobb, 2000).

\section{Findings}

We share the results in four sections: data on students' reasoning on the Cartesian Product, the Relations and the Function. Then, we provide data, at the end of the study, on students' reasoning on the questions assessing their constructed relationships among the three concepts.

\section{Section 1: The Cartesian Product}

The teacher wrote the following in her preparation prior to the teaching.

"In teaching of this concept, the matching of the elements of two sets needs to be established. But the teacher first needs to answer the following question "why do we macth two sets? This is because for the students to meaningfully learn the content, they need to make a relationship between real life examples. With this goal, they need to realize what ordered pairs mean and the ordered pairs' representing a point in the analytical system. We need to find such a good example so that the point's meaning need to be established by the students. This is also important for the students to realize because when they learn Function Graphs they will also learn about the matching elements between sets. This is important also for students' learning about limit as a point and neighboorhood of that point. Therefore, the following examples are used while teaching the Cartesian Product".

This suggests that the teacher's intention for her students was to give meaning to the ordered pairs through real life examples. With this goal, the teaching started with the following question and the students provided names from other classess.

Teacher: Let us find two students from each classroom in our high school and give those students numbers as 1. , 2. Let us show this using a table.

For instance;

\begin{tabular}{|l|l|l|}
\hline \multicolumn{1}{|c|}{ Classes } & 1. Person & 2. Person \\
\hline High school 1 & & \\
\hline High school 2 & & \\
\hline High school 3 & & \\
\hline High school 4 & & \\
\hline
\end{tabular}

Table 1: What is given to the students

Then the teaching wents as follows:

\begin{tabular}{|l|l|l|}
\hline Classes & 1. Person & 2. Person \\
\hline High school 1 & Hakan & Ceren \\
\hline High school 2 & Irem & Gizem \\
\hline High school 3 & Birkan & Zeynep \\
\hline High school 4 & Asrin & Serkan \\
\hline
\end{tabular}

Table 2: What students came up with. 
Teacher: If we needed to show the classes and the students in the coordinate system, how could we show each student?
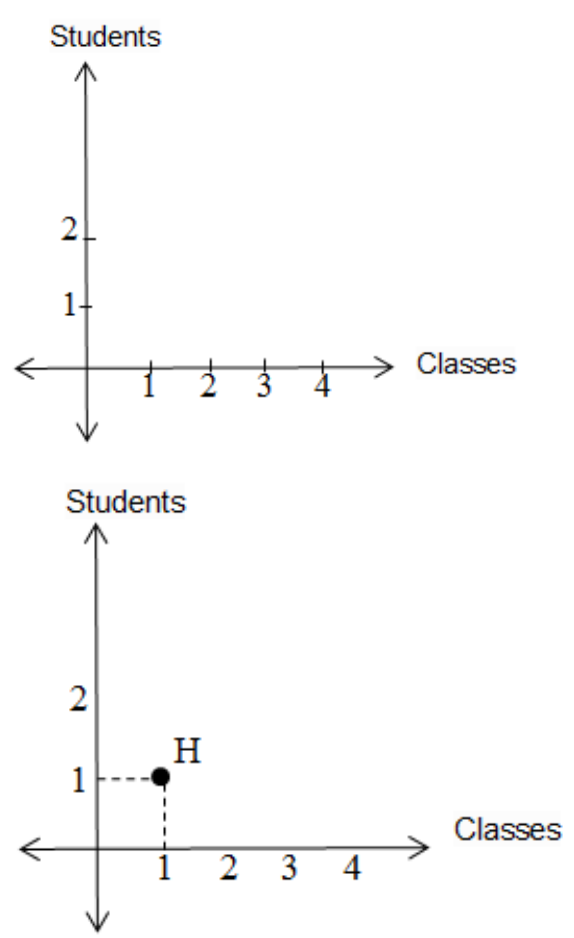

Teacher: (showing the $\mathrm{x}$ axis on the graph) how could we name this axis?

There was no answer from the students and the teacher cotinued:

Teacher: Should we name it as class or students?

S1: We can name it as Class.

Then the students and the teacher decided to name the $\mathrm{x}$ axis as classes and the $\mathrm{y}$ axis as the students. Then,

Teacher: Okay then. For example, how can we show Hakan from the 9th grade in the coordinate system?

One of the students Ceylin came to the table and showed $(1,1)$ on the coordinate system. Then put ' $\mathrm{H}^{\prime}$ with the help of the teacher. Then the students who wanted to come to the board, chose one student from the table, and showed their names on those points (see Figure-1).

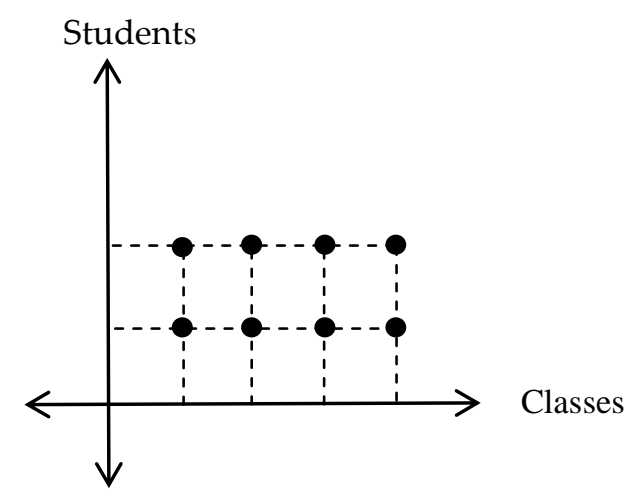

Figure 1. Students' showing the names of the students from other classes in the Table-2.

The excerpt above show that students engaged in a problem context that was relevant to their lives. This was an attempt at creating an awarenes on the students part such that the ordered pairs shown in the coordinate system refer to quantities, the classes and the students respectively, in life. This is important for students to realize. Although students did not know at first how to name the axis, with the teacher's question focusing on 'the classes' and 'the students', they were able to name each axis. Also, the data show that students were able to show each student in the Table-2 on the coordinate system. Then the discussion followed:

Teacher: Using the analytical system, for instance, if we would like to talk about Ceylin mathematically, how can we say it?

S2: 1,2

Teacher: All right then how can we write it? 


\section{S3 : $\{1,2\}$ (showing it on the board)}

What is interesting is that the student showed it on the board as $\{1,2\}$. This represents elements of a set rather than showing ordered pairs. This indicates that S3 did not know how to represent ordered pairs, but used his previous knowledge of the sets. Then the discussion continued:

Teacher: In sets, the places of the elements can change, but, what do you think about the elements' places changing in our example? That is, when we say 1,2 what do we mean?

S4: The first student from the 10th grade

Teacher: Okay then, what about 2,1

S4: The first student from the 10th grade.

Teacher: Do you think they are the same?

Whole class: No

Teacher: Then, we need to use a different representation than the set representation

Then the students remembered how to show the points on the analytical system from the 8th grade and S1 did the following on the board.

S1: $(1,2) \quad$ (showing it on the board)

Teacher: Okay, very good, so then how can we show Serkan?

Then the teacher called on all the students' names in the class and asked one student to show them mathematically on the board. Students were able to do this activity without any problem. The excerpt above show that connecting what they knew before,from the 8th grade, to what they are learning now, the mathematical representation of ordered pairs, students were able to show the ordered pairs on the analytical system. More importantly, they came to the realization that the point $(1,2)$ is not the same as $(2,1)$ on the coordinate system and they referred to quantities in life. Then the discussion followed:

Teacher: Now, let us show 'Classess" and "Students" as sets with Venn Diagram.



Figure 2.Teacher's representing Classes and Students

Teacher: How can we show the students that we chose with Venn Diagram? For instance how can ve show 54 with Venn Diagram?

S4:

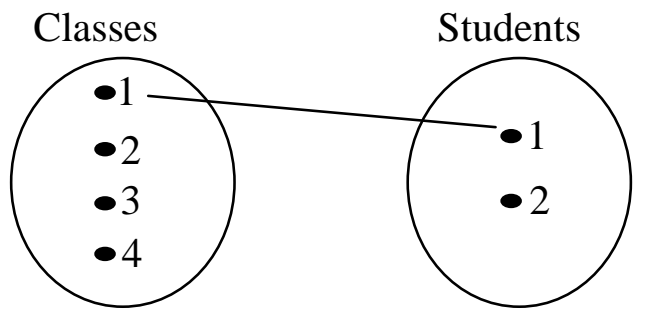

The interesting thing is that $\mathrm{S} 4$ howed it using a line segment rather than an array. The teacher then asked:

Teacher: Is this showing the direction from Students to Classes or Classes to Students, what to do you think? How can we determine the direction? Like, when we read $(1,1)$, how can we differentiate 
the first element's coming from the first set, like the Classes set? Like, how can we show the difference between $(1,2)$ and $(2,1)$ on the Venn Diagram?

S4: Ohh. We need to put an arrow. (coming to the board again).



The excerpt show that $S 4$ although did not use an arrow to show the ordered pair $(1,1)$ on the Venn diagram, with the teacher's taking his attention to the difference between the ordered pairs $(1,2)$ and $(2,1)$ realized how to show it on the Venn Diagram. Then the discussion followed:

Teacher: Let us show all the macthes between these two sets and show them as for instance $(1,1)$.

$(1,1),(1,2),(2,1),(2,2),(3,1),(3,2),(4,1),(4,2)$

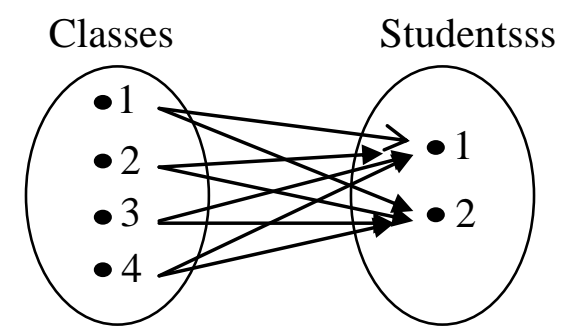

Figure 3.Students' showing the matches and pairs.

Students, who wanted to come to the board, showed all the macthes between the sets and the ordered pairs on Table-2. Then the teacher asked the following question and allowed for different students' reasoning.

Teacher: If we call what we have been doing with the sets, Classes and Students, as Cartesian Product, what do you think Cartesian Product mean?

S5: Multiplying the two sets' elements.

S6: Multiplying the number of elements in the sets

S3: Matching two sets.

Teacher: Very good. Cartesian Product means the macthes between all the elements of two sets, A and $\mathrm{B}$, and it is shown as AXB.

What is striking is that data show that some students were able to reason about the meaning of the Cartesian Product in a meaningful way and once the teacher realized that, she provided them with the mathematical definition. At that point, the teacher asked students to think about the representation of the Cartesian Product as a list. The students stated that the elements need to be in order. Then the teacher asked them how to represent Cartesian Product symbolically. Teacher wrote on the board the following $\mathrm{AXB}=\{(\mathrm{x}, \mathrm{y}) \mid \mathrm{x} \in \mathrm{A} \wedge \mathrm{y} \in \mathrm{B}\}$.

The teacher stated that students had really a hard time thinking about the symbol " $\wedge$ ". Then the teacher provided students with a few examples such as $A=\{1,2,3\} \quad B=\{a, b\}$ so that they could write $A X B$ ve $B X A$ as a list representation. Then the discussion followed:

Teacher: Do you think AXB and BXA are equal to each other?

Whole class: Noooo.

Teacher: What is the same about them? 
Whole class: Their number of elements.

Data is interesting because the whole class is able to think about the fact that AXB and BXA are not the same. That is, they reached the conclusion that the Cartesian Product does not have the commutative property. Yet, they knew that their numbers of elements are the same. What is unfortunate is that the teacher did not ask "why" they thought so. Although, the data suggests that that students were able to come to the conclusion based on the authors' choice of the real life example and the teacher's ongoing questioning regarding the importance of the order of the elements in the sets, still probing students' answers might have further evidenced their reasoning. Then the teacher asked them how to symbolically represent the fact that the Cartesian Products', AXB and BXA, number of elements are the same. One of the students wrote $\mathrm{s}(\mathrm{AXB})=\mathrm{s}(\mathrm{BXA})$. Then the teacher asked them

Teacher: how can we write s(AXB) symbolically then? (whole classes hands were on the air).

Teacher: Ok, well, then tell me how I can write it.

Teacher: $S(A X B)=s(A)$. $s(B)$ (with her students' help wrote on the board).

Teacher: Okay then. Tell me in how many ways we can show AXB and BXA?

Whole class: (slience for some time)

Teacher: One is as a list.

Whole Class: Two is Venn Diagram and the three is graphic. (almost all the class)

What is interesting about the excerpt above is that the teacher takes her students' point of attention to how they have been representing any Cartesian Product. Students had a hard time first stating it but once they understood what the teacher is asking then almost all of them were able to state the different representations of it.

So far what the data suggests is that, students' reasoning through a real life example, specifically thinking about their friends from different classrooms, situating their individual placements in the classes on the coordinate system, their engagement in representing the points on the coordinate system, on Venn Diagram and as a list provided these students with oppurtunities to develop three different but related key mathematical ideas about the Cartesian Product: the definition, the number of elements, and the commutativity property of it. Data also showed that students had difficulties in two ways: First, representing the ordered pairs such as $(1,2)$ and second, representing the ordered pairs in sets such as showing the order with arrows.

\section{Graphical Representation of The Cartesian Product}

During the second set of lessons, the teacher asked the following question:

Teacher: Let us start our lesson with the following question. If I have two sets, $A=\{4,5\}$ ve $B=\{-1,2,3\}$, could you find the number of elements in AXB and could you show it on the analytical system?

The S3 drew the following on the smart-board:

S3:

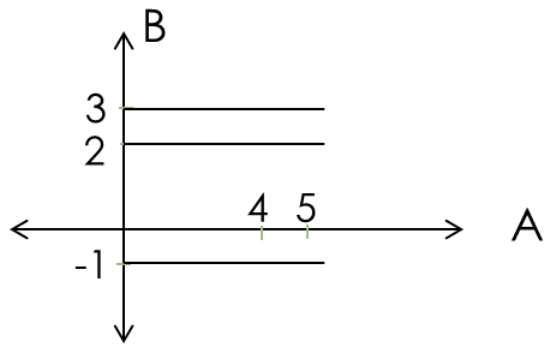

Figure 4. The S3's solution on the smart-board.

Teacher: How many points are there in this line (showing the one at the top)? 
S7: Too many

S6: Infinity

Teacher: Okay then, how many points would we like to show?

(A few students at the same time): 6 points.

Teacher: Okay then, can I show these points as a line?

S6: we can show it like before.

Then they showed it on GeoGebra (See Figure 5)

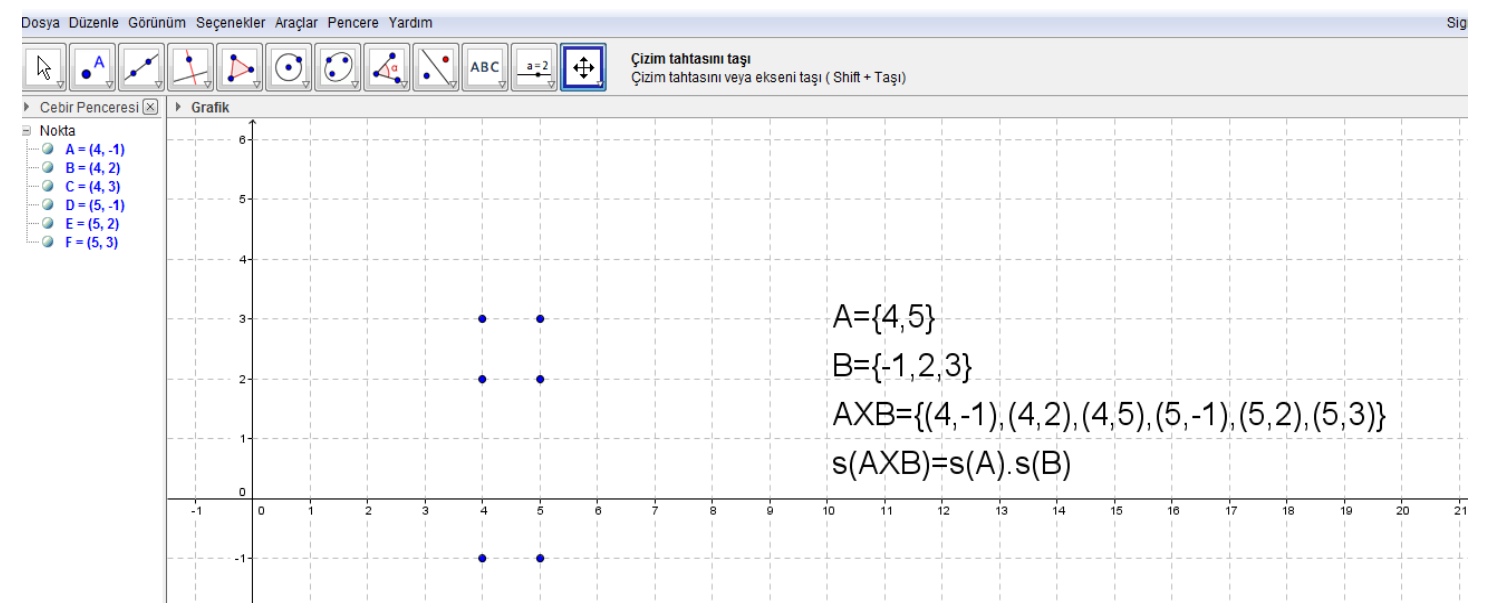

Figure 5. Teacher and the students' drawing AXB on GeoGebra.

Data indicate that although S3, as shown earlier, stated "matching two sets" for defining the Cartesian Product, he represented the AXB, given in two discrete sets, as a line. What this shows is that either S3 did not pay attention to the sets' discreteness or he represented the sets as what he knew from before. These students knew graphing linear functions on the coordinate system from 8th grade. The unfortunate thing is that the teacher did not ask him "why" he drew his graph as it in Figure-4. Though what this data shows that S3 had difficulty in representing the macthing of two discrete sets on the coordinate system. Then the discussion followed.

Teacher: If one of the sets in the Cartesian Product had infinetely many elements, how would its graph look like?

Whole class: A Line (shouting almost)

Teacher: Okay. Then think of a finite and an infinite set and draw AXB.

The teacher wrote as $A=\{x \mid 4 \leq x \leq 5, x \in I R\}$ and $B=\{-1,2,3\}$. Then the teacher asked:

Teacher: SO, let us think first of all how to create the point $(4,-1)$, and then think about how we can create another point right near 4 , also it with thinking -1 . What would that number be?

Whole class: 4.1(talking altogether as a chorus, hard to distinguish voices)

Teacher: Okay, so we have the ordered pairs $(4.1,-1)$ too. What next then?

Whole class: $(4.2,-1),(4.3,-1),(4.4,-1) \ldots \ldots$ ( talking altogether as a chorus, hard to distinguish voices)

Then the teacher showed the first point on GeoGebra and asked students help her. She first let them see the points zooming in (See Figure-6) and then zooming out (See Figure-7) 


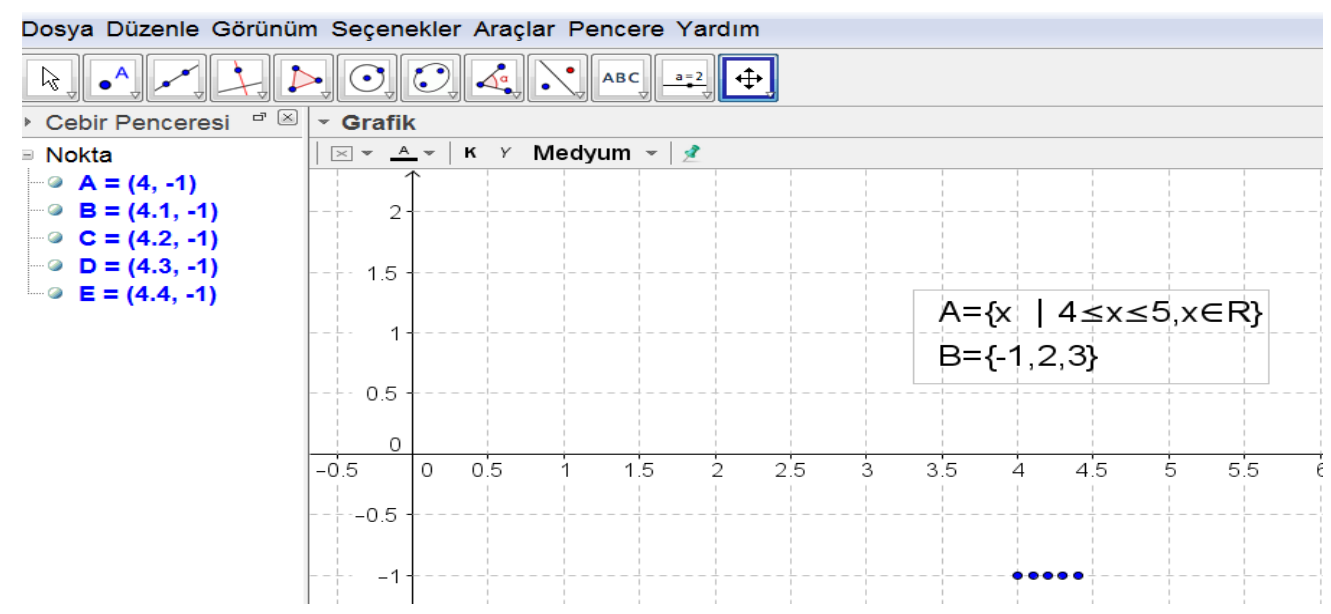

Figure 6. The teacher's and the students' drawing the points on GeoGebra, together.
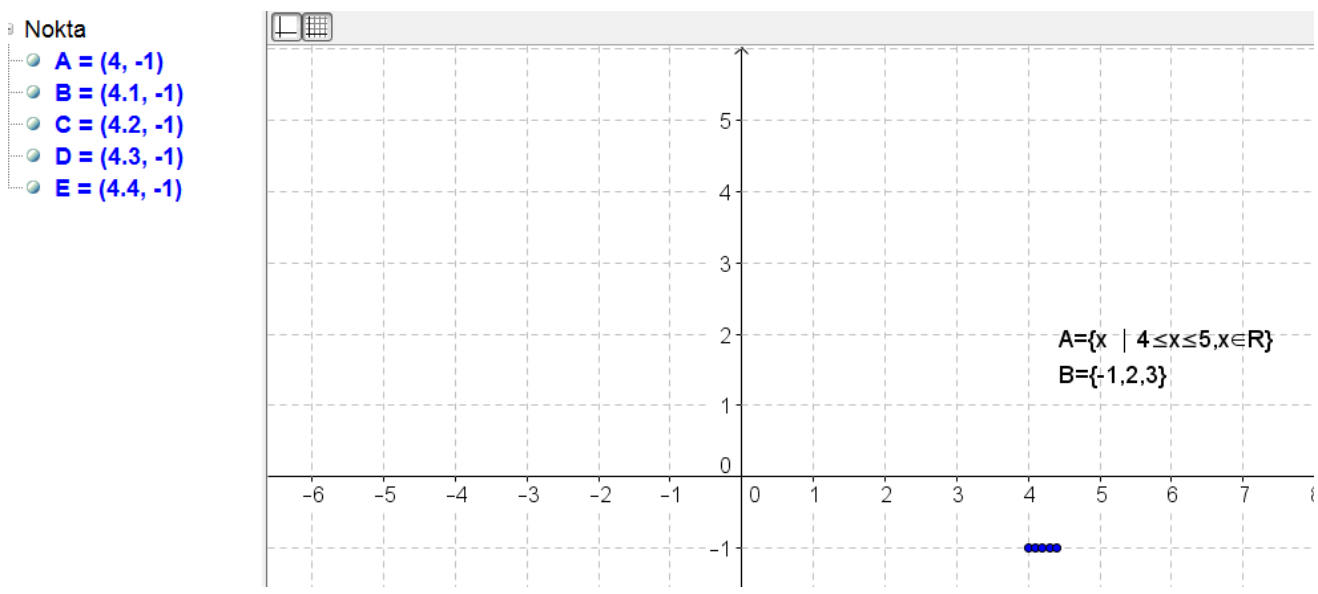

Figure 7. The teacher's zoomin out the graph on GeoGebra.

What is interesting about the excerpts above is that all the students are aware of the fact that the macthing of a finite and an infinite set will represent a line. Though, the teacher's taking students' attention on how to do that on the GeoGebra is important. Researchers claimed that students have difficulty in realizing that they macth two ordered pairs while drawing a line graph. This is especially because students are generally given two ordered sets of points to draw a line graph and their awereness of the other points (infintely many) being also ordered pairs matched together fades out. In this regard, the teacher attempts at taking her students' focus to how a line graph is established given a finite set and an infinite set. Then the teacher asked students to complete the exact graph given the two sets of $A=\{x \mid 4 \leq x \leq 5, x \in I R\}$ and $\mathrm{B}=\{-1,2,3\}$.

Teacher: Okay then, if we continue like this what kind of a graph will it be? Now, I want everyone to draw it.

One student drew the following:

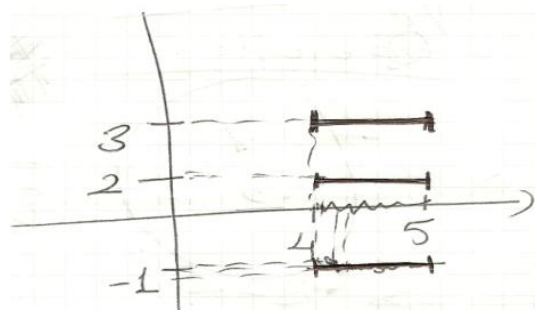

Figure 8. One student's working on the graph of $A=\{x \mid 4 \leq x \leq 5, x \in \operatorname{IR}\} B=\{-1,2,3\}$.

Teacher: What if the two sets had infinetly many points, how would the graph look like? 
S5: There will be two lines

S4 : There will be three lines.

S1: There will be many lines.

Data show that students are having difficulties in imagining the Cartesian Product of two infinite sets. S1 seems to think of many lines, yet, it is not clear from the data how she imagines that, whether as an area or as many lines distinct from each other.

Teacher: Okay then, let us think of two infinite sets like A and B and let us draw AXB. Then she wrote on the board the following: $A=\{x \mid 4 \leq x \leq 5, x \in I R\}$ and $B=\{x \mid-1 \leq x \leq 3, x \in I R\}$. The she stated:

Teacher: Let us first note that these two sets are infinite sets. Let us match these sets first. First, try to draw this macthing.

Then students drew their graphs, one of which follows. We share this data since this is a typical of what other students drew too. Also, the students did not write their names on the papers.

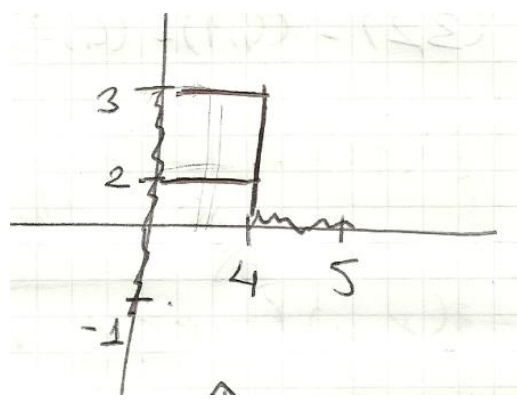

Then the teacher asked them to draw it on the GeoGebra together (See Figure 10).
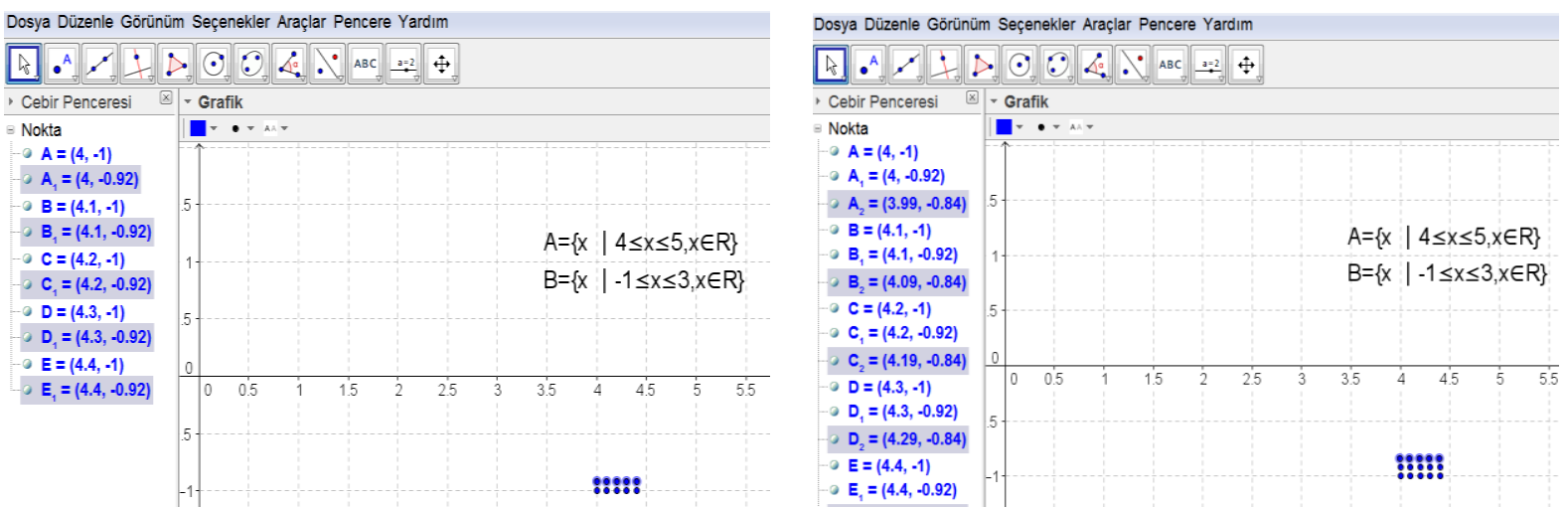

Figure 10. The teacher and the students' drawing the points on GeoGebra (zooming in)

First, they talked about the points $4,4.1,4.2, \ldots$ being very close to each other and matching with -1 . Then, they talked about the same points' $4.0,4.1,4.2,4.3$...being macthed with the points very close to the point -1. After they did the same thing for a few times, they zoomed out on GeoGebra (See Figure 11). 


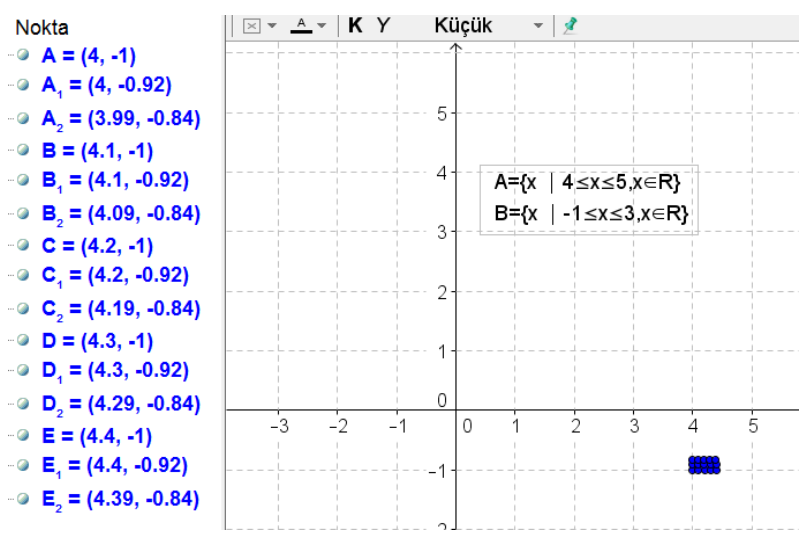

Figure 11. The teacher's zooming out the graph on $\{x \mid-1 \leq x \leq 3, x \in I R\}$
Teacher: What about if we continue like this. What kind of a graph will we get? Draw it.



Figure 12. One student's drawing

Students drew it. We show the same student's example (in Figure 9) as a representation since it examplifies a true drawing (See Figure 12). Though the teacher stated that students still had difficulty in drawing the graph at their first attempt.

Data show that students have difficulty in thinking about macthing of two infinite sets (the Cartesian Product) at first. However, after the GeoGebra activity with the teacher, they are able to construct the graph. This shows that GeoGebra might help students overcome their difficulties in graphing the Cartesian Product of two infinite sets.

\section{Section 2: Relations}

In the following teaching session, the teacher started the lesson as follows:

Teacher: Okay, let us start our lesson with writing the Cartesian Product from the Students' set to the Drinks set. Let us just use their initials while writing it.

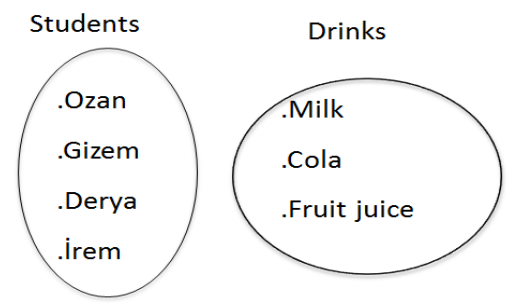

Figure 13. The set of Students and the Drinks.

The teacher wrote the following on the board with her students' help.

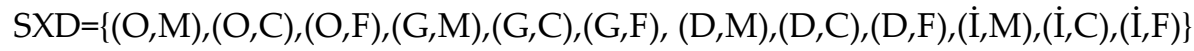

Teacher: If the students wanted to choose the drinks on their own, what matching could you come up with? Give examples.

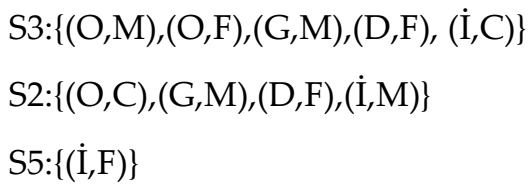

Teacher: Now discuss with your friends whether your examples are the subsets of the Cartesian Product between the elements of these two sets? Why?

The students discussed with their friends and came to the conclusion that their examples were sub sets of the Cartesian Product, SXD.

Teacher: If we call these sub sets as Relation, what could the mathematical definition of a relation? 
S1: A subset

Teacher: Whose subset is it?

S1: The subset of the Cartesian Product.

Data show that S1 could state the definition of the relation. Then the teacher gave them the formal definition of the relations as follow:

Teacher: Any subset of a Cartesian Product, $\mathrm{A} \times \mathrm{B}$, of the sets $\mathrm{A}$ and $\mathrm{B}$ is called a relation from $\mathrm{A}$ to $\mathrm{B}$.

Then the discussion followed:

Teacher: Okay, now, I want you to draw the Cartesian Product defined on the set $A=[1,3]$.

One student example follows (See Figure 14)

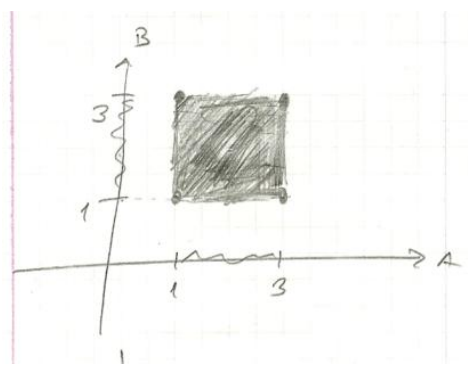

Figure 14. One student's drawing the Cartesian Product on the set $A=[1,3]$.

And the teacher asked the students the following:

Teacher: Could you construct any relation within this Cartesian Product?

Some student examples follow (See Figure 15).


Figure 15. Some examples from students' drawings

What is striking about students' drawings is that they drew all forms of the Cartesian Product: matching between two finite sets, matching between a finite and an infinite set and matching between two infinte sets. Also, the data show that they understand that these are subsets of the Cartesian Product defined on the infinite set, $A=[1,3]$. 


\section{Section 3: Defining Function}

This section show data on students' development of the definition of function from two perspectives: based on relations and based on the variables, respectively. The teacher started the first set of lessons on function with the following real life example.

Teacher: Let us do the macthing between two sets based on a rule. For example, let us define a problem for the matching between the elements of the following two sets. If you were asked to determine the busses the 3 students in a school can sit going on a school picnic, what matchings would you come up with? (See Figure 16)
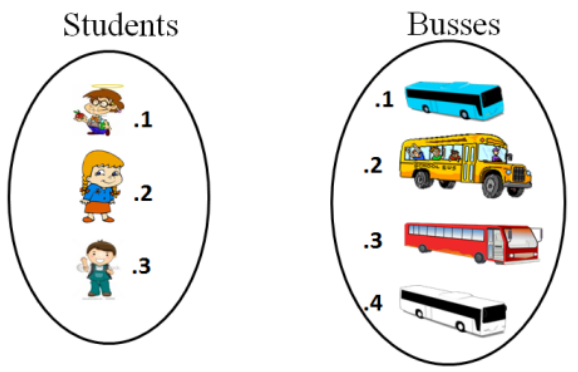

Figure 16. The first set shows the Students and the second set shows Busses.

Students came up with the matchings and then the teacher asked them the following:

Teacher: If the examples you came up with are matchings between these two sets, are they subsets of the Cartesian Product between these two sets? Why?

S1: Yes. Because they are relations.

Teacher: Okay then, if they are relations, let us write them on the board.

Data is interesting because the Student1 was able to reason about the relationship between the subset of a Cartesian Product and the relation. That is, what data shows is that Student1 understood that once a set is a relation, then it has to be a subset of a Cartesian Product.

Then the teacher wrote the following on the board based on the students' answers.

$$
\begin{aligned}
& \text { Example1 }=\{(1,1),(2,2),(3,3)\} \\
& \text { Example2 }=\{(1,1),(2,1),(3,2)\} \\
& \text { Example3 }=\{(1,2),(2,2),(3,2)\} \\
& \text { Example4 }=\{(1,2),(2,2),(3,4)\}
\end{aligned}
$$

Teacher: We defined any subset of a Cartesian Product between two sets as relations. If we construct relations from the set of 'Students' to the set of 'Busses' like Example1 $=\{(1,1),(1,3),(2,3),(3,4)\}$ or Example2 $=\{(1,1),(2,3)\}$, then there is a problem with these.

Whole class: In the first one the first student was sent to the first and the third busses. (almost all of them talking).

S3: In the second one, the third student was not sent anywhere.

Teacher: So then we can say such relations are not the ones that we like, can't we?

Then the teacher provided the students with the following: She showed them the Figure 17 and told them that we call the Students set as the domain set, we call the Busses set as codomain set and the set of possible placements on the Busses set as range. 


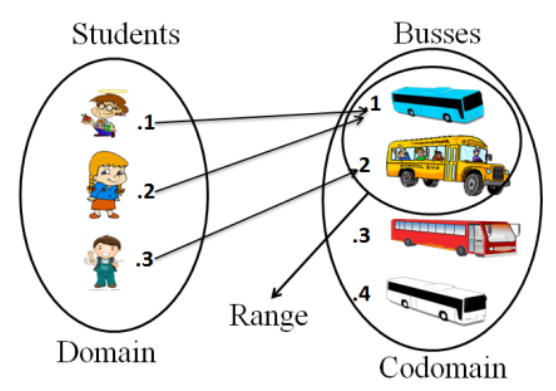

Figure 17. The teacher's showing the Domain, the codomain, and the range

Teacher: Thinking the problem of placing a student on the busses, if we call the matchings between these two sets as Function, what kind of a relation should we construct from the domain set to the codomain set so that we can call it as a function?How can we define this kind of a relation mathematically?

S1: The relation relating the elements of the domain to the only one element of the codomain.

Teacher: Do you think this will be enough?

S3: The relation taking all the elements of the domain to only one element of the codomain.

The teacher then gave the mathematical definition of function as

Teacher: Great. The relation taking every element of the domain to one and only one element of the codomain is called a function.

Data show that Student 1 and Student 3 understood that function is a relation. Also, it shows that they realize the restirictions of both the elements of the domain and the range. This also shows that the real life example putting the restriction on students' placements on busses to be able to go to the school picnic provided students with an opportunity to realize the definition of function as "A function is a relation in which each element of the domain is paired with exactly one element of the range" (Cooney, et.al., 2011).

Students' first thinking about their examples as subsets of a Cartesian Product and as a relation, and then their thinking about function as a relation also indicate that these students might have developed the function definition as "A function is a set of ordered pairs (or number pairs) that satisfies this condition: There are no two ordered pairs with the same input and different outputs" (Cooney et.al., 2011).

Then the teacher continued with the following example:

Teacher: So far, whe have chosen our domain and codomain sets on our own. For instance, we thought of which student would be matched with a bus. Now, can we determine the elements of the range according to a mathematical rule?

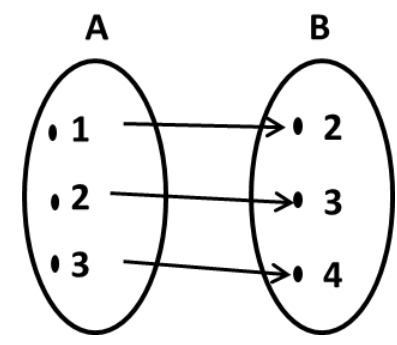

Figure 18. The teacher's example

Teacher: What rule can determine for the range in this example?

Some students: Always one more

Teacher: If we put 4 in the domain set, which element in the codomain this element would be taken to? 
Some students:5

Teacher: If we call the elements of the domain set as ' $x$ ' and the elements of the codomain as ' $y$ ', can we determine the relationship between $\mathrm{x}$ and $\mathrm{y}$ ?

Some students: Always taking one more, so $\mathrm{x}+1$.

The fact that students were able to state "always taking to one more, so $x+1$ " shows that these students realize that $x$ and $x+1$ values co-vary together because a student can imagine all input at once or "run through a continuum of inputs. A function is a transformation of entire spaces in the process view of function, as opposed to realizing it as action, where" a student can only imagine a single value at a time as input or output (e.g., $x$ stands for a specific number).

At this point one important but a subtle issue needs to be given further attention: The teacher provided the students with a relatively simple example so that they could come up with the $y=x+1$. Although students were able to state what the elements of the range would be always $x+1$, the teacher commented that students were not able to state " $=$ " the equal sign. She speculated that a teacher might need to ask "what y is equal to?", rather than asking the relationship between $\mathrm{x}$ and $\mathrm{y}$. As much as this might be the case, we also accounted for this difficulty in the following way: The equal sign ," $="$, have different meanings such as "a signal to compute" or "to assign meaning to a variable" (Usiskin, Peressini, Marchisotto \& Stanley, 2003). Thus the data might be taken as evidincing that students might have difficulty in thinking about the equal sign in terms of assigning meaning to a variable.

Then the teaching continued with a real life example again, assigning kg to Turkish Liras. The teacher discussed how to represent functions with the symbols based on this example. She stated

Teacher: We will represents the functions with the symbols like $f, g, h$. And we will write $f(x)=y$ : relation $\mathrm{f}$ takes all the elements of the domain, say $\mathrm{x}$, to one and only one element of the range, say $\mathrm{y}$.

They then discussed independent and dependent variables, and also the teacher asked students to think of the real life example in terms of equality sign, $f(x)=30 x$. Then they drew the graph of the function together on the board. After this point, the teacher had a discussion on all the representations of the a function; namely, Venn Diagram, list, common property, table and graphic.

Then the teaching continued with another task on GeoGebra, graphing $f=\{(x, y) \mid y=-2 x+1, x \in R\}$. Then they assigned some some values to $x$ and found $y$ values on a table (See Figure 19) and showed these on the graph on GeoGebra (See Figure 20).

\begin{tabular}{|c|c|}
\hline$x$ & $y$ \\
\hline 0,1 & 0,8 \\
\hline 0,2 & 0,6 \\
\hline 0,3 & 0,4 \\
\hline 0,4 & 0,2 \\
\hline 0,5 & 0 \\
\hline
\end{tabular}

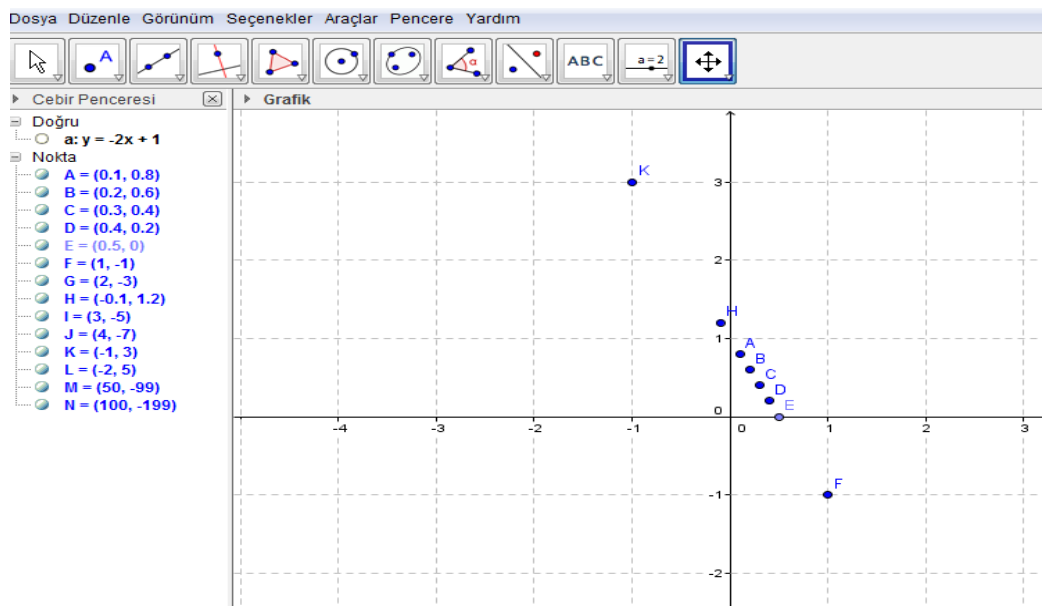

Figure 19. Table representation of $f(x)=-2 x+1$

Figure 20. Graphic representation of $f(x)=-2 x+1$ 
The teacher and the students, as they did earlier while graphing the Cartesian Product two infinite sets, first assigned specific values to $x$ (zooming in, See Figure 20). Then, the teacher zoomed out (See Figure 21) the grahical representation of the function on GeoGebra to show students that the graphical representation of a function with an infinite domain and infinite range might create a line.



Figure 21. The teacher's zoomin out the graph of $f(x)=-2 x+1$ on GeoGebra.

Teacher: If we have found all the ordered pairs on this function in the analytical plane, how would the graph look like:

Whole class: A line (shouting)

Teacher: Okay then draw that line in your notebooks.

Data indicate that students realized the function graph as a line. Unfortunaltely, the students' graphs were not collected.

\section{Section 4: Assessment Questions}

The teacher asked students to answer some assessment questions two weeks after the function definition instruction. Since the class was a small group, the teacher projected the assessment problem on the board and did a group-interview with them. The assessment question was as follows:

Teacher: You are given graphics of relations defined on the set $A=[1,3]$ (from A to A). Explain for each of them whether these graphs represent a Cartesian Product, a relation and a function. Give your reasoning.

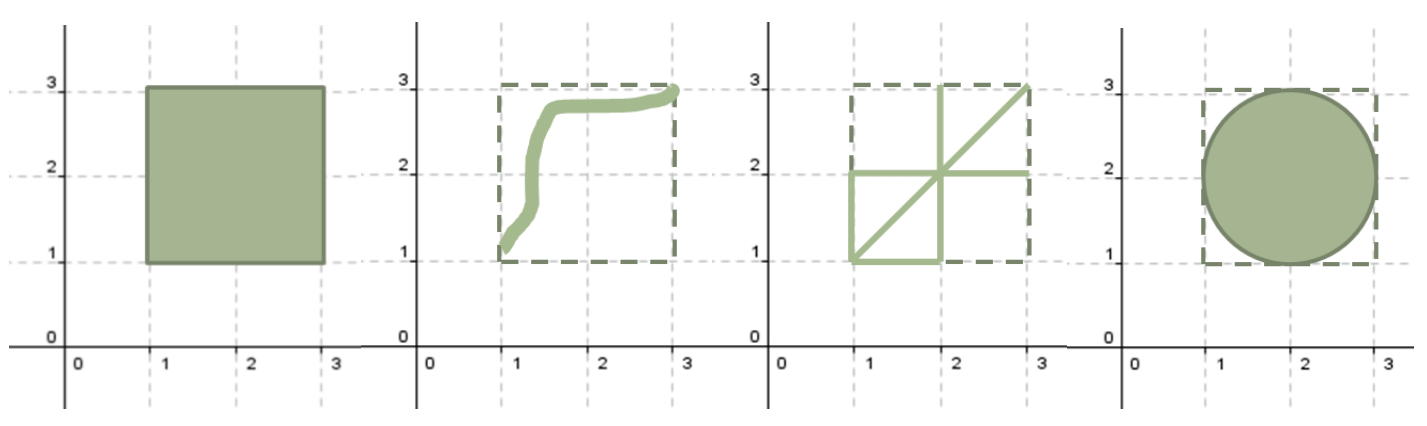

- Cartesian Product.

- Relation

- Function 
We share one student answers as shown below since this has been typical of others.

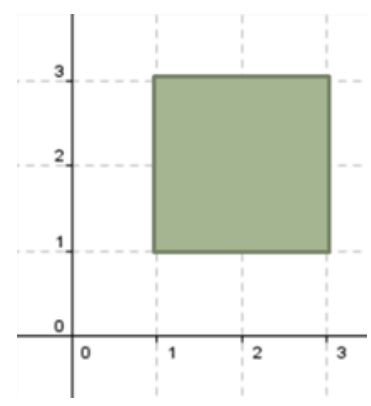

Cartesian Product: Yes Cartesian Product because it is created by macthing two sets.

Relation: Yes, because every Cartesian Product is a relation.

Function : It is not a function. For example, 3 has gone to too many values.

Data indicate that the student especially has grasped the relationship between the relation and the Cartesian Product. Data show that she thinks of Cartesian Product as a subset of itself and therefore thinks of it as a relation too.

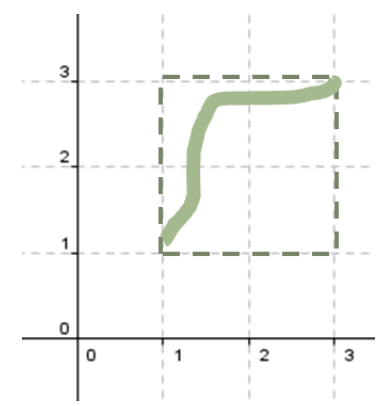

Cartesian Product: No it is not a Cartesian product because all the macthings are not done.

Relation: Yes because it is drawn in the Cartesian Product.

Function: It is a function, because it is not like on top of each other, there is only one result for each.

Data show that the student thinks of this graph as a subset of the graph of the Cartesian Product in the previous one and thinks of this as a relation. By the same token, for her the function is a relation such that, in her own word "for each" element (of the domain) has to be associated with, in her own words "result", one and only one element of the range.



Cartesian Product:No, it is not a Cartesian Product, the whole macthing is not there.

Relation: Yes, it is drawn in the Cartesian.

Function: It is not a function because for example 2 has gone to both 2 and 3.

The student continues to think the same way such that for two infinite sets to construct a Cartesian Product, for her, the whole macthing has to be there. Again, it is a relation because it is a subset of it.

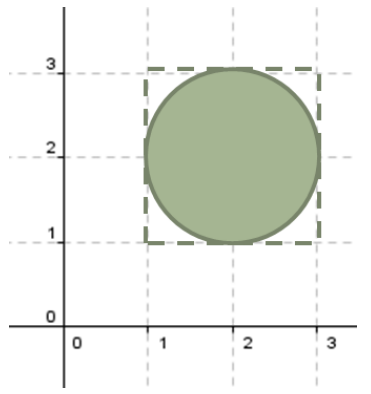

Cartesian Product: No, whole macthing is not there.

Relation: Yes, it is in the Cartesian.

Function: It is not a function, it is shaded. 
What is striking about the data above is that, the student thinks of the area of a shape as not exemplifying a function. This suggests that, for her, a Cartesian Product might not be a function.

\section{Discussion}

In this study we investigated how six 9th grade students come to the recognizing the relationship between Cartesian Product, relations and the definition of function. Also, we accounted for the changes in students' thinking through situating the tasks they engaged in.

Data indicated that although, students at the beginning of the Cartesian Product did not know that the order (of the pairs) is important, they were able to differentiate that given some tasks. In particular, at the beginning when the teacher asked students to situate the initials of their friends from different classrooms, one student first showed it using the set representation. This in fact corresponds with the historical development of the Cartesian Product. Historically, the ordered pairs, first, were represented using the set representation \{\} , and then the modern representation "( )" was started to be used (Narll, 2013). The reason for the change in the representational use was the same: the need to pay attention to the order, $(x, y)$ and $(y, x)$ showing two different points in the analytical system. This was in align with this research results in the sense that the students also needed to pay attention to the need for ordering the points since once the order changed the real life situation the points attributed to changed. That is, the points referred to the classes ( $x$ axis) and the students in these classes (y axis). Once the order of the paired quantities changed then the meaning also has changed. Bayazit (2010) stated that students generally have difficulty in interpretting a function's representation in an ordered pair $(x, y)$ since they generall think of the elements in an ordered pair showing no relationhsip with each other. This research results suggest that teachers need to take their students' attention to the order of the pairs using real life situations compatible with their own lives so that they attribute meaning to them and think of a relationship between them. In addition, data showed that although students seem to realize the importance of order in one representation such as "()", they might not necessarily transfer this to the other representations. For instance, data showed that some students first used a line segment to show the correspondance between elements of two sets while making sense of the Venn Diagram representation of the Cartesian Product between two finite sets. Only after the teacher's focused questioning, students realized that an arrow needs to be used to show the direction of the macthing between the elements of sets. This suggests that teachers need to be aware of such difficulty on the students part, too. Also, data showed one student drew a line for the grapical representation of the matching between two finite sets. This finding aligns with the students' misconceptions about their interpretting the discrete data as if it was a continious one (e.g., Dunham \& Osborne, 1991) and thinking of a function graph as a continous line without taking the context into consideration (e.g., Tall \& Bakar, 1992). Though data showed that focused questioning and students' engagement in GeoGebra tasks, zooming in and out on the graphs, might have helped them overcome their difficulties with interpretting line graphs. We claim this because data showed that although at the beginning a student drew four connecting lines, a circumference, for the macthing of the elements of two infinite sets, she was able to construct a graph of a plane for the Cartesian Product defined on two infinte sets after the GeoGebra Task. In addition, data showed that students were able to define a relation as a subset of a Cartesian Product and was able to give examples. The interesting point was that students were able to show macthings between two sets. By the same token, one student example showed that for her not only a relation was the subset of a Cartesian Product but also a Cartesian Product was a relation (the reciprocal relationship between them).

Results regarding the definition of function showed that students seemed to develop two different definitions: based on the correspondance between ordered pairs and a relation. In particular, one student provided a definition of function as "The relation relating the elements of the domain to the only one element of the codomain" and another student stated "The relation taking all the elements of the domain to only one element of the codomain". They also came to these definitions based on their reasoning on the ordered pairs representation of relations. Data also showed that some students were able to think of the input and output relationship as imagination of all input at once or running through a continuum of inputs (Cooney et.al., 2011). This was because some students were able to state "always taking to one more, so $x+1$ " while thinking about the relationship between the elements of the domain and the co-domain, as co-varying 
quantities (Carlson \& Oehrtman, 2005). Data further suggested that students had difficulty in writing, for instance $y=x+1$. This might be taken as evidince that students might have difficulty in thinking about the equal sign in terms of assigning meaning to a variable.

\section{Implications and Limitations}

Some limitations of the study follow: At one point students' individual responses were collected without paying attention to students' names. Also, at another point, students' individual responses were not collected. This might have been due to the fact that the first researcher was not able to attend to the teaching sessions. Interviews done with the students at the end of the study could have provided means to overcome such defect. Still, the teacher attended to student' reasoning during the teaching sessions regularly and based on the retrospective analysis evidence on six students' development of the relationships among these concepts could be determined to some extent.

Data indicated that students had some difficulties while developing the Cartesian Product and the definition of function. In particular, students were not able to easily recognize that the Cartesian Product of the elements of two infinite sets create an area. Instead, they thought of lines, many lines while thinking about that and they even provided a circumference rather than an area model to represent it. However, after engaging in the GeoGebra task with the teacher focusing on how to create such correspondance between the elements of two infinite sets, one student was able to construct an area model. Yet, after the teaching session, the teacher stated that although GeoGebra task were helpful, the students still had difficulty in creating such representation. Thinking that the teacher and the students were not using the GeoGebra simultaneously, future research by letting students use the GeoGebra might be done to investigate how to overcome such difficulty on their part. In addition, results indicated that students have difficulty in using the equal sign, " $="$, in terms of assigning a meaning to a variable.

Data showed that once the teacher asked the question as "what is the relationship between $\mathrm{x}$ and $\mathrm{y}^{\text {", }}$ the students were not able to state the equality between " $=$ " them. Rather, once the teacher asked the question as "what is y equal to" then the students were able to answer is as $y=x+1$. This suggests that students might be only thinking about the meaning of equal sign in terms of finding a result. Further research investigating the relationship between students' understandings of the equal sign and the function concept might be conducted.

In addition, results indicated that the transfer of the knowledge on the order of the number pairs in a Cartesian Product of two finite sets might not necessarily be transferred to other representations such as Venn Diagram. Teachers need to be attentive to this while teaching the concept.

\section{References}

Bayazıt, I. (2010). Fonksiyonlar konusunun öğreniminde karşılaşılan zorluklar ve çözüm önerileri, Matematiksel Kavram Yanilgilari ve Cözüm Önerileri, Ed. (M.F. Özmantar, E. Bingölbali. H.Akkoc), s. 91-119. Pegem Yayınclik: Ankara.

Bayazıt, I. \& Aksoy, Y. (2013). Fonksiyon kavramının matematiksel manası ve tarihsel gelişimi, I. O. Zembat, M. F. Özmantar, E. Bingölbali, H. Şandır, ve A. Delice (Editörler), Tanımları ve Tarihsel Gelişimleriyle Matematiksel Kavramlar, (s. 339-352). Pegem Yayıncilik: Ankara.

Breidenbach, D., Dubinsky, E., Hawks, J., \& Nichols, D. (1992). Development of the process conception of function. Educational Studies in Mathematics, 23, 247-285.

Carlson, M.P., \& Oerthman, M. (2005). Key aspects of knowing and learning the concept of function. The MathematicalAssociation of America (MAA),(p.1-17).Downoadable on internet at https://maa.org/t_and_1/sampler/rs_9.html\#m92.

Carlson, M. P., Smith, N., \& Persson, J. (2003). Developing and connecting calculus students' notions of rate of change and accumulation: The fundamental theorem of calculus. In N. A. Pateman, B. J. Dougherty, \& J. T. Zilliox (Eds.), Proceedings of the 2003 Joint Meeting of PME and PMENA, Vol. 2 (pp. 165-172). Honolulu, HI: CRDG, College of Education, University of Hawai'i. 
Carlson, M., Jacobs, S., Coe, E., Larsen, S., \& Hsu, E. (2002). Applying covariational reasoning while modeling dynamic events: A framework and a study. Journal for Research in Mathematics Education, 33(5), 352-378.

Carlson, M. P. (1998). A cross-sectional investigation of the development of the function concept. In A. H. Schoenfeld, J. Kaput, \& E. Dubinsky (Eds.), Research in Collegiate Mathematics Education. III. CBMS Issues in Mathematics Education (pp. 114-162). Providence, RI: American Mathematical Society.

Cobb, P. (2000). Conducting teaching experiments in collaboration with teachers, In A. E. Kelly \& R. A. Lesh (Eds.), Handbook of research design in mathematics and science education (p. 307-333). Mahwah, NJ: Lawrence Erlbaum Associates, Publishers.

Cooney, T.J., Beckmann, S., Lloyd, G.M., Wilson, P.S., \& Zbiek, R.M. (2011). Developing essential understanding of functions for teaching mathematics in grades 9-12. The National Council of Teachers of Mathematics: Reston, VA.

Dabbah, M., Nurlu, Z., \& Önder, H.A. (1992). Calculus 1 for Math Students. ODTÜ. Ankara.

Dubinsky, E., \& Harel, G. (1992). The nature of the process conception of function. In G. Harel \& E. Dubinsky (Eds.), The concept of function: Aspects of epistemology and pedagogy. MAA Notes, 25, 85-106.

Dunham, P. H., and Osborne, A. (1991). Learning how to see: Students' graphing difficulties. Focus on Learning Problems in Mathematics, 13(4), 35-49.

Eccles, J.P. (1997). An introduction to mathematical reasoning-Numbers, sets and functions. (p. 115- 125). London, UK: Cambridge university Press.

Karagöz Akar, G. (2013). Oran-orantı kavram tanımları, rasyonel rayılar içerisindeki yeri ve doğrusallık kavramı ile ilişkisi, I. O. Zembat, M. F. Özmantar, E. Bingölbali, H. Şandır, ve A. Delice (Editörler), Tanımları ve Tarihsel Gelişimleriyle Matematiksel Kavramlar, (p.111-126). Pegem Yayıncılık: Ankara.

Karagöz Akar, G. (2009). Oran konusunun kavramsal öğreniminde öğrencilerin karşılaşabileceğgi zorluklar, olası kavram yanılgıları ve çözüm önerileri, E. Bingolbali \& F.M. Ozmantar (Eds.), İlköğretimde Karşılaşılan Matematiksel Zorluklar ve Çözüm Önerileri, (p. 267-289). Pegem Yayıncllık: Ankara.

Leinhardt, G., Zaslavsky, O., \& Stein M. (1990). Functions, Graphs and Graphing: Tasks,Learning and Teaching. Review of Educational Research , 60(1), 37-42.

Narlı, S. (2013). Bağıntı kavramı ve bu kavrama temel teşkil eden kavramlar, I. O. Zembat, M. F. Özmantar, E. Bingölbali, H. Şandır, ve A. Delice (Editörler), Tanımları ve Tarihsel Gelişimleriyle Matematiksel Kavramlar, (s. 309-328). Pegem Yayıncilık: Ankara

Sfard, A. (1991). On the dual nature of mathematical conceptions: Reflections on process and objects as different sides of the same coin. Educational Studies in Mathematics, 22, 1-36

Tall, D. \& Bakar, M. (1991). Students' mentaş prototypes for functions and graphs. Downloadable on internet at http://www.warwick.ac.uk/staff/David.Tall/pdfs/dot1991f-mdnor-function-pme.pdf

Usiskin, Z., Peressini, A., Marchisotto, E.A., \& Stanley, D. (2003). Mathematics for High School Teachers: An Advanced Perspective. New Jersey: Printice Hall. 